\title{
Balance trainer training with transcutaneous electrical nerve stimulation improves spasticity and balance in persons with chronic stroke
}

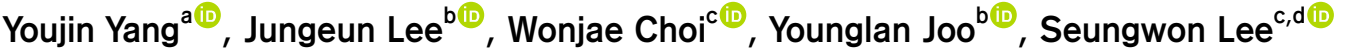 \\ ${ }^{a}$ Department of Physical Therapy, Wonju Medical Center, Wonju, Republic of Korea \\ ${ }^{b}$ Department of Physical Therapy, Graduate School of Physical Therapy, Sahmyook University, Seoul, Republic of Korea \\ Institute of SMART Rehabilitation, Sahmyook University, Seoul, Republic of Korea \\ ${ }^{d}$ Department of Physical Therapy, College of Health Science and Social Welfare, Sahmyook University, Seoul, Republic of Korea
}

Objective: The purpose of this study was determine the effect of Balance Trainer training with Transcutaneous Electrical Nerve Stimulation (TENS) on spasticity and balance in persons with chronic stroke.

Design: Randomized controlled trial.

Methods: A total of 30 subjects with hemiparetic stroke were recruited and randomly divided into the Balance Trainer training with TENS group $(\mathrm{n}=15)$ and Balance Trainer training with placebo TENS group $(\mathrm{n}=15)$. The Balance Trainer training with TENS group practiced additional Balance Trainer training with TENS for 30 minutes a day, 5 days per a week during 4 weeks and the Balance Trainer training with placebo TENS group practiced additional Balance Trainer training with placebo TENS for the same period. Spasticity and balance were assessed by ability (static balance, dynamic balance) and were measured before and after the 4-week programs.

Results: The result of spasticity and dynamic balance were improved significantly in both groups $(p<0.05)$. The Balance Trainer training with TENS group showed significantly greater improvement in spasticity of the gastrocnemius \& dynamic balance, compared to the Balance Trainer training with placebo TENS group $(p<0.05)$. The Balance trainer training with TENS group showed a significant improvement in static balance, especially during the eye-closed condition $(p<0.05)$.

Conclusions: The Balance Trainer training with TENS was effective in improving spasticity and balance in subjects with chronic stroke. Based on these results, it is suggested that Balance Trainer training with TENS could clinically be used more actively in conjunction with conventional physical therapy.

Key Words: Muscle spasticity, Postural balance, Stroke, Transcutaneous Electrical Nerve Stimulation

\section{Introduction}

The representative issues after a stroke incidence is muscle weakness, abnormal muscle tension, and disorder of balance and postural control. In particular, balance issues are the most important problem to address since balance is necessary for daily life activities after a stroke incidence [1,2]. Recovery of balance ability is one of most important goals of rehabilitation treatment.
Balance ability is defined as the ability to maintain the centroid of a body in the base area, and it is an ability required in all functional daily life activities [3]. Most individuals with stroke experience difficulty in balance control because postural disturbance increases during standing due to asymmetry of body alignment caused from differences in muscle strength between the paretic side and the non-paretic side [4]. Also, the degree of muscle tension, which increases due to spasticity, generates balance disorders

Received: 20 May, 2020 Revised: 29 May, 2020 Accepted: 2 June, 2020

Corresponding author: Seungwon Lee (ORCID https://orcid.org/0000-0002-0413-0510)

Department of Physical Therapy, College of Health Science and Social Welfare, Sahmyook University, 815 Hwarang-ro, Nowon-gu, Seoul 01795 , Republic of Korea Tel: 82-2-3399-1630 Fax: 82-2-3399-1639 E-mail: swlee@syu.ac.kr

(c) This is an Open-Access article distributed under the terms of the Creative Commons Attribution Non-Commercial License (http://creativecommons.org/licenses/ by-nc/4.0) which permits unrestricted non-commercial use, distribution, and reproduction in any medium, provided the original work is properly cited.

Copyright ( 2020 Korean Academy of Physical Therapy Rehabilitation Science 
and the loss of this balance ability heightens secondary risks, such as experiencing injuries from a fall, and limits the performance of daily life activities [5,6]. Spasticity is an activated pattern dependent on speed and appears to be related with a decrease in control of suppressive mechanism because of a decrease in threshold of the stretch reflex and an increase in amplitude of the stretch reflex [7]. Spasticity may lead to secondary changes such as rigidity, fibrosis, and muscle atrophy [8]. In particular, functional defects of the lower limbs, which appear together with clubfoot, becomes a hindrance factor against successful rehabilitation. They incur balance disorders during walking [9].

As biofeedback training provides information on body movement and space relation, it is effective in improving balance control, provides motivation and concentration to patients through diverse programs, and is possible for same and repetitive implementation [10]. Matjacic et al. [11] proposed a new approach method of balance training through the biofeedback program during standing by using the Balance Trainer. The Balance Trainer provides a safe balance environment and assists with muscle activation of ankle and hip joints. It is hypothesized that to promote spasticity inhibition, the use of transcutaneous electrical nerve stimulation (TENS) may decrease hyper-excitability, modulate reciprocal inhibition, and increase in presynaptic inhibition [12-14]. Another hypothesis is to arouse the decline of sensitivity by decreasing central excitation, which is accompanied with excitability of the lower cortex motor neurons, and declination of sensitivity is generated [14]. Namely, this somatosensory stimulation can be a useful method to treat motor disturbance related to the increased motor excitability and can reorganize the damaged cortex [15]. So, as the approach method will inhibit spasticity and lead to voluntary muscular contraction, it will accelerate motor relearning through the mechanism of neural plasticity [16]. In a previous study, Jung et al. [17] reported that sit-to-stand training with TENS training improved spasticity, postural balance, and muscle strength in stroke survivors. This study included a TENS group and a sham TENS group, and the intensity was applied at the sensory threshold level in the TENS group. When stimulating the subjects at the sensory threshold level, a tingling sensation could be felt, which was different with the TENS group [17].

Therefore, the purpose of this study was to investigate the effects of using the Balance Trainer and applying sub-threshold TENS onto the lower limbs on decreasing spasticity and improving balance ability in individuals with stroke.

\section{Methods}

\section{Participants and procedure}

This was a randomized controlled pilot Among the 30 patients receiving treatment from a rehabilitation center after being diagnosed with stroke, those who satisfied next conditions were selected as subjects for this study.

The inclusion criteria were as follows: (1) first episode of unilateral stroke; (2) a Mini-Mental State Examination score of 24 or higher; (3) have been over six months after the onset of stroke; (4) can understand and follow intervention contents.

The exclusion criteria were as follows: (1) hearing disorder; (2) hemianopia, dizziness, or other symptoms indicating vestibular impairment; (3) other neurological disorders or orthopedic diseases which affect balance; (4) have participated in a study similar to this study within the past year.

All participants were evaluated and screened using the inclusion and exclusion criteria. Informed consent was voluntarily obtained from all patients before participation in the study, and this study was approved by the Institutional Review Board of Sahmyook University (SYUIRB2013-043).

Sample sized was calculated by G* power v3.1.0 (Franz Faul, University of Kiel, Kiel, Germany) with an alpha level of 0.05 and power of 0.8. Effect size was estimated on spasticity in the previous study [17], with a large effect size (Cohen's $d=2.37$ ). A more conservative effect size of 1.0 was selected and therefore, the total sample size was calculated to be 28 subjects ( 14 per group) to detect significant between-groups differences. The sample size was set to 30 (15 subjects per group) considering dropouts.

Subjects were randomly assigned to the experimental group $(n=15)$ or the control group $(n=15)$. To generate random allocation, a person who was not involved in the study picked out a numbered stick (either 1 or 2) from a sealed envelope. All subjects were evaluated on their spasticity, dynamic balance, and static balance before and after the 4week training period.

The experimental group conducted the Balance Trainer training with TENS and the control group conducted the Balance Trainer training with placebo TENS for 30 minutes, 5 times per week for 4 weeks, respectively (Figure 1).

\section{Intervention}

The Balance Trainer (Balance-trainer, 2011; Medica medizintechnik, Hochdorf, Germany) is a device to be designed possible for weight shift into anterior, posterior, me- 


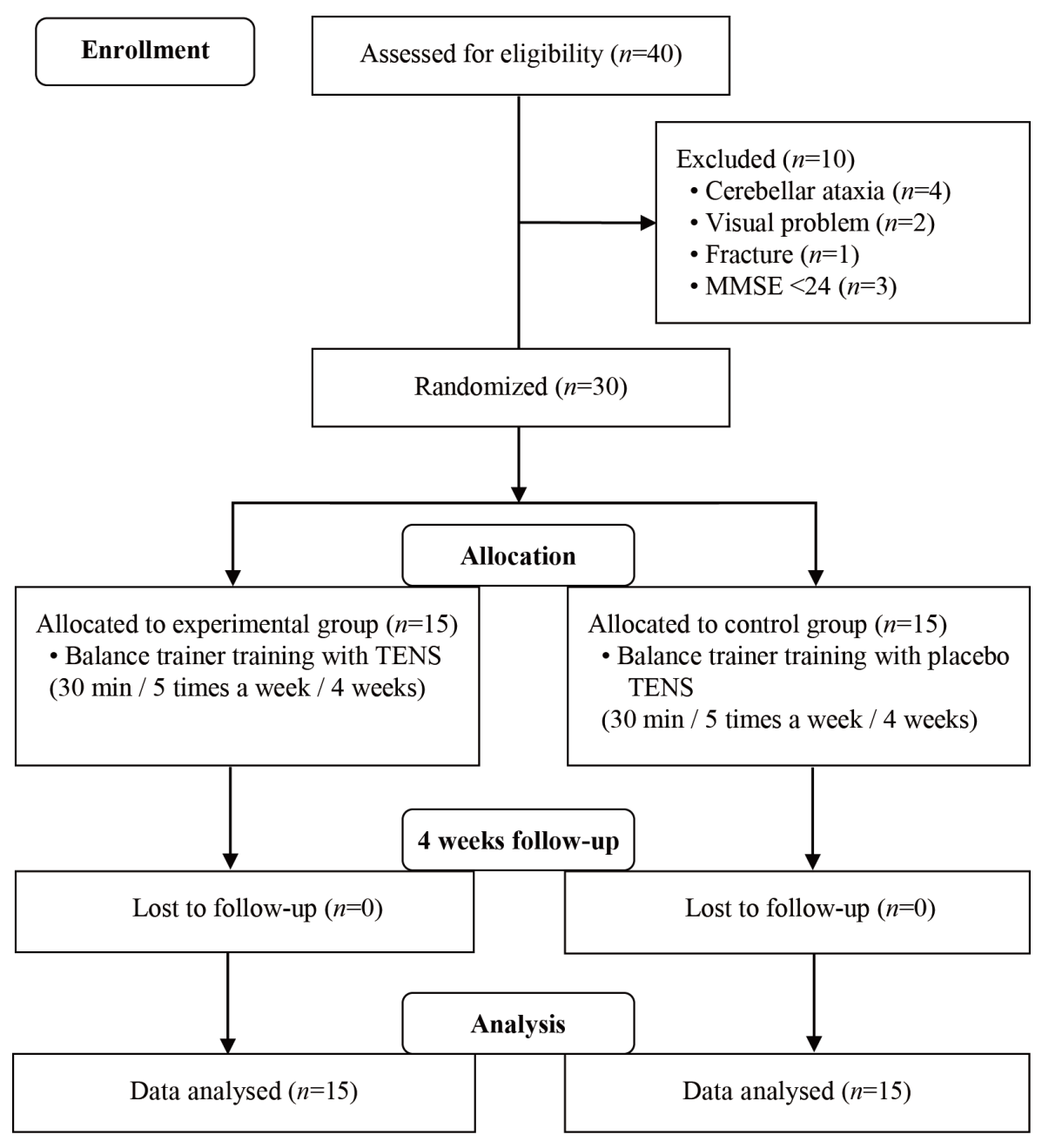

Figure 1. CONSORT flowchart for experimental procedure. MMSE: minimental state examination, TENS: Transcutaneous Electrical Nerve Stimulation. dial, lateral, and diagonal directions. Mechanical supports were applied to the participants' knees and pelvis and were adjusted according to the individual's abilities [11]. In the standing state and by using a visual biofeedback program through front monitors, balance training using the Balance Trainer was implemented. The program was composed of three programs such as the anterioposterior training, the mediolateral training, and the eight-direction training in anterior, posterior, medial, lateral, and diagonal directions. Each training session was conducted for 10 minutes, totaling up to 30 minutes. When the average score improved by over $80 \%$ each week, the training intensity was increased by one level of each program.

For the TENS application, a two-channel TENS (TENS7000, 2006; Koalaty Products Inc., Tampa, FL, USA) was used. The adhesive TENS electrodes $\left(5 \mathrm{~cm}^{2}\right)$ were applied onto the medial and lateral bellies of the gastrocnemius of both lower limbs of the subjects. The stimulation was per- formed with biphasic symmetrical pulses, frequency of 100 $\mathrm{Hz}$, and pulse width of $200 \mu \mathrm{s}$. The intensity was implemented starting from $0.01 \mathrm{~mA}$ in order to measure the sensory threshold of each subject to the size of $90 \%$ level of thresholds of senses of each individual in stimulation after investigating the thresholds, which the subjects had felt [18]. TENS stimulation was applied along with Balance Trainer training. Non-stimulating placebo TENS was applied onto the control group. All subjects reported having no feeling with the placebo TENS.

\section{Outcome measurements}

For the spasticity test, the most common scale used for muscle tonus assessment is the Modified Ashworth Scale (MAS). For better evaluation, the MAS was developed by the addition of one grade $(+1)$ to the original Ashworth Scale [19]. In this study, muscle tension of the gastrocnemius of the subjects was measured. The subjects were made to 
feel comfortable in a supine position. Inspectors measured muscle tension repeatedly three times by applying passive stretching into the direction towards the instep of the ankles. Ankle ROM indicates the possible range of motion that exists in the ankle joint. For the measurement, a goniometer (Goniometer; Otto Bock, Duderstadt, Germany) with a unit of two degrees was used. With the subjects lying comfortably in supine position, the inspector assessed ankle dorsiflexion range using a goniometer.

To assess dynamic balance ability, the functional reach test (FRT) is a test method used to measure the farthest distance of the arm stretched forward maximally in standing position. It is a reliable tool with a test-retest reliability of $\mathrm{r}=0.89$ and an inter-rater reliability of $\mathrm{r}=0.98$ [20]. The Timed Up and Go Test (TUG) is a measurement tool used to measure basic motility and balance. It is a reliable tool with an intra-rater reliability of $\mathrm{r}=0.99$ and an inter-rater reliability of $\mathrm{r}=0.97$ [21].

As a method to measure static balance ability, the Good Balance System (Good Balance System, 2008; Metitur Ltd., Jyväskylä, Finland) was used. This device is composed of a movable triangular force plate for bipedal standing and a safety bar. On the force plate, a graduated ruler is marked for the proper location of the feet. The device is used to examine balance or rehabilitation training, such as postural sway or weight bearing. The device has been used broadly to measure balance of athletes, elderly persons, or individuals with stroke and uses the function of wireless short area networks [22]. In the test-retest method, the intra-rater coefficient was 0.83 or greater, and high reliability was proved.

\section{Data analysis}

PASW Statistics for Windows, Version 18.0 (SPSS Inc., Chicago, IL, USA). The general characteristics of subjects

Table 1. General characteristics of subjects

$$
(\mathrm{N}=30)
$$

\begin{tabular}{lccc}
\hline \multicolumn{1}{c}{ Variable } & $\begin{array}{c}\text { Experimental } \\
\text { group }(\mathrm{n}=15)\end{array}$ & $\begin{array}{c}\text { Control group } \\
(\mathrm{n}=15)\end{array}$ & $\chi^{2} / \mathrm{t}$ \\
\hline Sex (male/female) & $11 / 4$ & $6 / 9$ & 0.136 \\
Paretic side (left/right) & $9 / 6$ & $9 / 6$ & 1.000 \\
Age (y) & $61.53(9.24)$ & $63.33(9.43)$ & 0.602 \\
Body weight (kg) & $65.50(8.01)$ & $61.40(8.20)$ & 0.177 \\
Height (cm) & $163.33(6.02)$ & $162.47(5.65)$ & 0.688 \\
Duration after stroke (mo) & $16.67(5.38)$ & $17.33(11.91)$ & 0.845 \\
Type (infarct/hemorrhage) & $5 / 10$ & $7 / 8$ & 0.556 \\
\hline
\end{tabular}

Values are presented as number only or mean (SD). are presented as mean and standard deviation values and the test for normality was conducted for all subjects. As a result, all data presented normal distribution. For the homogeneity of the experiment group and control group, an independent t-test and chi-square test was conducted. The paired t-test was used for within-group comparison and the independent t-test was used for between-group comparison. The level of statistical significance was set at 0.05 .

\section{Results}

The general characteristics of the subjects are shown in Table 1. Participant characteristics across groups were relatively similar.

In both groups, the paired t-test revealed significant differences in MAS and range of motion of the ankle joints and there were significant differences between the two groups $(p<0.05)$ (Table 2). In the experimental group, dynamic and static postural balance was significantly improved compared with the baseline and control group except for postural sway in the eye-open condition $(p<0.05)$ (Table 3$)$. In the control group, dynamic postural balance was significantly improved compared with the baseline. However, static postural balance was significantly different in the anteroposterior and velocity moment with the eye-open condition $(p<0.05)$ (Table 3$)$.

\section{Discussion}

The purpose of this study was to investigate the effects of Balance Trainer training with TENS on spasticity and postural balance in persons with chronic stroke. A significant

Table 2. Change of ankle spasticity in the two groups $(\mathrm{N}=30)$

\begin{tabular}{|c|c|c|c|}
\hline Ankle spasticity & $\begin{array}{l}\text { Experimental } \\
\text { group }(n=15)\end{array}$ & $\begin{array}{l}\text { Control group } \\
\qquad(\mathrm{n}=15)\end{array}$ & $\mathrm{t}$ \\
\hline \multicolumn{4}{|c|}{ MAS of ankle joint (score) } \\
\hline Pre-test & $3.27(0.88)$ & $3.60(0.82)$ & -1.066 \\
\hline Post-test & $2.31(0.74)^{*}$ & $3.20(0.86)^{*}$ & \\
\hline Changes & $1.14(0.74)$ & $0.40(0.50)$ & $-3.157 * *$ \\
\hline \multicolumn{4}{|c|}{ ROM of ankle dorsiflexion $\left(^{\circ}\right)$} \\
\hline Pre-test & $5.07(2.21)$ & $4.60(2.53)$ & 0.537 \\
\hline Post-test & $10.47(3.62)^{*}$ & $6.07(3.57)^{*}$ & \\
\hline Changes & $5.40(3.06)$ & $1.47(2.13)$ & $4.078^{* *}$ \\
\hline
\end{tabular}

Values are presented as mean (SD).

MAS: Modified Ashworth Scale, ROM: ranges of motion.

* Significant difference between pre-test and post-test $(p<0.05)$.

**Significant difference between the two groups $(p<0.05)$. 
Table 3. Change of balance in the two groups

$(\mathrm{N}=30)$

\begin{tabular}{|c|c|c|c|}
\hline Postural balance & $\begin{array}{l}\text { Experimental } \\
\text { group }(n=15)\end{array}$ & $\begin{array}{l}\text { Control group } \\
\qquad(\mathrm{n}=15)\end{array}$ & $\mathrm{t}$ \\
\hline \multicolumn{4}{|l|}{ Dynamic balance } \\
\hline \multicolumn{4}{|l|}{ TUG (second) } \\
\hline Pre-test & $26.21(10.55)$ & $26.86(18.31)$ & -0.118 \\
\hline Post-test & $19.57(6.29)^{*}$ & $24.70(17.09)^{*}$ & \\
\hline Changes & $6.64(5.51)$ & $2.16(2.65)$ & $-2.843 * *$ \\
\hline \multicolumn{4}{|l|}{ FRT (cm) } \\
\hline Pre-test & $18.08(4.26)$ & $19.30(5.79)$ & -0.654 \\
\hline Post-test & $23.67(5.11)^{*}$ & $21.51(5.97)^{*}$ & \\
\hline Changes & $5.59(3.38)$ & $2.21(2.71)$ & $3.005^{* *}$ \\
\hline \multicolumn{4}{|l|}{ Static balance } \\
\hline \multicolumn{4}{|l|}{ Eye open } \\
\hline \multicolumn{4}{|c|}{ Anteroposterior $(\mathrm{mm} / \mathrm{s})$} \\
\hline Pre-test & $7.82(3.57)$ & $7.87(2.79)$ & -0.038 \\
\hline Post-test & $5.39(3.13)^{*}$ & $6.51(3.29)^{*}$ & \\
\hline Changes & $2.43(2.18)$ & $1.36(1.66)$ & -1.521 \\
\hline \multicolumn{4}{|c|}{ Mediolateral (mm/s) } \\
\hline Pre-test & $10.51(4.58)$ & $11.38(3.98)$ & -0.550 \\
\hline Post-test & $7.62(3.31)^{*}$ & $9.89(4.46)$ & \\
\hline Changes & $2.89(2.82)$ & $1.49(3.40)$ & -1.235 \\
\hline \multicolumn{4}{|c|}{ Velocity moment $\left(\mathrm{mm} / \mathrm{s}^{2}\right)$} \\
\hline Pre-test & $29.55(16.18)$ & $29.10(15.11)$ & 0.078 \\
\hline Post-test & $19.11(15.10)^{*}$ & $24.27(17.66)^{*}$ & \\
\hline Changes & $10.44(10.03)$ & $4.83(7.25)$ & -1.755 \\
\hline \multicolumn{4}{|l|}{ Eye close } \\
\hline \multicolumn{4}{|c|}{ Anteroposterior $(\mathrm{mm} / \mathrm{s})$} \\
\hline Pre-test & $12.79(8.44)$ & $10.25(4.42)$ & 1.031 \\
\hline Post-test & $8.30(5.47)^{*}$ & $8.87(4.16)$ & \\
\hline Changes & $4.49(4.03)$ & $1.38(3.11)$ & $-2.364 * *$ \\
\hline \multicolumn{4}{|c|}{ Mediolateral (mm/s) } \\
\hline Pre-test & $17.77(5.99)$ & $16.76(6.81)$ & 0.432 \\
\hline Post-test & $12.46(5.59)^{*}$ & $14.96(5.83)$ & \\
\hline Changes & $5.31(3.68)$ & $1.80(5.30)$ & $-2.107 * *$ \\
\hline \multicolumn{4}{|c|}{ Velocity moment $\left(\mathrm{mm} / \mathrm{s}^{2}\right)$} \\
\hline Pre-test & $64.73(66.47)$ & $44.46(29.61)$ & 1.079 \\
\hline Post-test & $32.90(38.23)^{*}$ & $38.00(24.99)$ & \\
\hline Changes & $31.83(32.40)$ & $6.46(17.08)$ & $-2.682 * *$ \\
\hline
\end{tabular}

Values are presented as mean (SD).

TUG: Timed Up and Go Test, FRT: functional reach test.

* Significant difference between pre-test and post-test $(p<0.05)$.

$* *$ Significant difference between the two groups $(p<0.05)$.

improvement in spasticity and postural balance was found. TENS can effectively decrease spasticity in individuals with stroke. When exercise and electrical stimulation are combined rather than a single intervention, it can be suggested that an additional effect is generated more greatly. Increase of abnormal muscle tension of the ankle plantar flexor muscles at lower limbs that appears in stroke survivors makes it difficult to have active control of dorsiflexion and generates changes of secondary soft tissues such as contracture as a result of prolonged contraction [23,24]. These generate changes in kinetic characteristics such as changes in connective tissues properties around the joints, changes in histochemical properties of spastic muscles, loss of sarcomeres, and restructure of connective tissues in muscles [25]. Due to these changes, the range of motion of joints is restricted, motor disturbance which causes muscle weakness is made, and functional movement of the body is hindered $[24,26]$. In a previous study, when high frequency TENS was applied to rats with spinal cord injury, it was said that secretion of gamma-aminobutyric acid as an inhibitory neurotransmitter at the spinal dorsal horn increased and spasticity decreased [27]. TENS stimulation decreased spasticity by facilitating presynaptic inhibition on the peroneal or sural nerves since the calf muscles are innervated by the sural nerve, which is made up of branches of the tibial nerve and the common perineal nerve [28].

According to this study, as TENS controls spasticity which appears from excessive excitement of the stretch reflex, it is estimated that anti-spasticity effect was shown. It is thought that effect on anti-spasticity between existing studies and this study was represented differently by diverse factors, such as application intensity of TENS, periods, frequency, and application location. In future studies, proper methods should be examined.

In this study, after 4 weeks of training, the TUG and the FRT were assessed for dynamic balance ability. By using the Good Balance System, static balance ability, such as anterioposterior posture sway velocity, mediolateral posture sway velocity, and velocity moment, were measured.

Posture control requires three senses, such as vestibulum, vision, and somatosensory. In a state that visual feedback is blocked, more dependence is placed on the somatosensory sense. Therefore, increase of balance ability in a condition of closed eyes is closely related with somatosensory input, which increased through TENS. TENS stimulation of the gastrocnemius, which is the center that acts on the maintenance and control of the standing posture, is thought to create an increased somatosensory input. It is said that somatosensory input through stimulus incurred electrically can increase restructure of the motor cortex via the anatomical connection between the sensory and motor cortices [29].

Hence, in this study, it is estimated that as TENS stimulation through lower limbs increases somatosensory information and changes the excitability of the cerebral cortex, it increases balance and produces effective movement. 
Through the study result, the experimental group showed decreased spasticity and increased balance ability in subjects with stroke. These results may suggest that it is more effective electric stimulation and active exercise programs are combined rather than implementing an exercise program or TENS independently. It is expected that this study will be useful data in establishing TENS as a standard protocol.

This study had some limitations. First, due to a small sample size, it is difficult to generalize the information obtained from this result. Second, the follow-up period was short and therefore, future studies with larger number of subjects and longer follow-up periods are needed. In addition, further studies verifying suitable methods of training programs accompanied with stimulus locations, application intensity, periods, frequency, and time of TENS application are necessary.

In conclusion, in this study, Balance Trainer training with TENS improved spasticity and postural balance in individuals with chronic stroke. The feasibility of Balance Trainer training with TENS has clinical importance for the chronic stroke population. Balance Trainer training with TENS provides additional benefits to therapists in that it is a safe and convenient to implement.

\section{Acknowledgements}

This paper was supported by Sahmyook University.

\section{Conflict of Interest}

The authors declared no potential conflicts of interest with respect to the authorship and/or publication of this article.

\section{References}

1. Carr JH, Shepherd RB, Nordholm L, Lynne D. Investigation of a new motor assessment scale for stroke patients. Phys Ther $1985 ; 65: 175-80$.

2. Goljar N, Burger H, Rudolf M, Stanonik I. Improving balance in subacute stroke patients: a randomized controlled study. Int J Rehabil Res 2010;33:205-10.

3. Sibley KM, Straus SE, Inness EL, Salbach NM, Jaglal SB. Balance assessment practices and use of standardized balance measures among Ontario physical therapists. Phys Ther 2011;91:158391.

4. Walker C, Brouwer BJ, Culham EG. Use of visual feedback in retraining balance following acute stroke. Phys Ther 2000;80:88695 .
5. Doan QV, Brashear A, Gillard PJ, Varon SF, Vandenburgh AM, Turkel CC, et al. Relationship between disability and health-related quality of life and caregiver burden in patients with upper limb poststroke spasticity. PM R 2012;4:4-10.

6. Lord SE, Rochester L. Measurement of community ambulation after stroke: current status and future developments. Stroke 2005; 36:1457-61.

7. Cheng JS, Yang YR, Cheng SJ, Lin PY, Wang RY. Effects of combining electric stimulation with active ankle dorsiflexion while standing on a rocker board: a pilot study for subjects with spastic foot after stroke. Arch Phys Med Rehabil 2010;91: 505-12.

8. Dietz V, Sinkjaer T. Spastic movement disorder: impaired reflex function and altered muscle mechanics. Lancet Neurol 2007;6: $725^{-} 33$.

9. Thibaut A, Chatelle C, Ziegler E, Bruno MA, Laureys S, Gosseries O. Spasticity after stroke: physiology, assessment and treatment. Brain Inj 2013;27:1093-105.

10. Yavuzer G, Eser F, Karakus D, Karaoglan B, Stam HJ. The effects of balance training on gait late after stroke: a randomized controlled trial. Clin Rehabil 2006;20:960-9.

11. Matjacić Z, Rusjan S, Stanonik I, Goljar N, Olensek A. Methods for dynamic balance training during standing and stepping. Artif Organs 2005;29:462-6.

12. Martins FL, Carvalho LC, Silva CC, Brasileiro JS, Souza TO, Lindquist AR. Immediate effects of TENS and cryotherapy in the reflex excitability and voluntary activity in hemiparetic subjects: a randomized crossover trial. Rev Bras Fisioter 2012;16:337-44.

13. Kim TH, In TS, Cho HY. Task-related training combined with transcutaneous electrical nerve stimulation promotes upper limb functions in patients with chronic stroke. Tohoku J Exp Med 2013;231:93-100.

14. Tinazzi M, Zarattini S, Valeriani M, Romito S, Farina S, Moretto $\mathrm{G}$, et al. Long-lasting modulation of human motor cortex following prolonged transcutaneous electrical nerve stimulation (TENS) of forearm muscles: evidence of reciprocal inhibition and facilitation. Exp Brain Res 2005;161:457-64.

15. Mima T, Oga T, Rothwell J, Satow T, Yamamoto J, Toma K, et al. Short-term high-frequency transcutaneous electrical nerve stimulation decreases human motor cortex excitability. Neurosci Lett 2004;355:85-8.

16. Bütefisch C, Hummelsheim H, Denzler P, Mauritz KH. Repetitive training of isolated movements improves the outcome of motor rehabilitation of the centrally paretic hand. J Neurol Sci 1995;130:59-68.

17. Jung KS, In TS, Cho HY. Effects of sit-to-stand training combined with transcutaneous electrical stimulation on spasticity, muscle strength and balance ability in patients with stroke: a randomized controlled study. Gait Posture 2017;54:183-7.

18. Park J, Seo D, Choi W, Lee S. The effects of exercise with TENS on spasticity, balance, and gait in patients with chronic stroke: a randomized controlled trial. Med Sci Monit 2014;20:1890-6.

19. Gregson JM, Leathley M, Moore AP, Sharma AK, Smith TL, Watkins CL. Reliability of the Tone Assessment Scale and the modified Ashworth scale as clinical tools for assessing poststroke spasticity. Arch Phys Med Rehabil 1999;80:1013-6.

20. Duncan PW, Weiner DK, Chandler J, Studenski S. Functional reach: a new clinical measure of balance. J Gerontol 1990;45: 
M192-7.

21. Whitney SL, Marchetti GF, Schade A, Wrisley DM. The sensitivity and specificity of the Timed "Up \& Go" and the Dynamic Gait Index for self-reported falls in persons with vestibular disorders. J Vestib Res 2004;14:397-409.

22. John LT, Cherian B, Babu A. Postural control and fear of falling in persons with low-level paraplegia. J Rehabil Res Dev 2010; 47:497-502.

23. Chan KS, Liu CW, Chen TW, Weng MC, Huang MH, Chen CH. Effects of a single session of whole body vibration on ankle plantarflexion spasticity and gait performance in patients with chronic stroke: a randomized controlled trial. Clin Rehabil 2012;26: 1087-95.

24. Sheean G, McGuire JR. Spastic hypertonia and movement disorders: pathophysiology, clinical presentation, and quantification. PM R 2009;1:827-33.
25. O’Dwyer NJ, Ada L, Neilson PD. Spasticity and muscle contracture following stroke. Brain 1996;119(Pt 5):1737-49.

26. Rydahl SJ, Brouwer BJ. Ankle stiffness and tissue compliance in stroke survivors: a validation of Myotonometer measurements. Arch Phys Med Rehabil 2004;85:1631-7.

27. Maeda Y, Lisi TL, Vance CG, Sluka KA. Release of GABA and activation of $\operatorname{GABA}(\mathrm{A})$ in the spinal cord mediates the effects of TENS in rats. Brain Res 2007;1136:43-50.

28. Cho HY, In TS, Cho KH, Song CH. A single trial of transcutaneous electrical nerve stimulation (TENS) improves spasticity and balance in patients with chronic stroke. Tohoku J Exp Med 2013;229:187-93.

29. Wu CW, van Gelderen P, Hanakawa T, Yaseen Z, Cohen LG. Enduring representational plasticity after somatosensory stimulation. Neuroimage 2005;27:872-84. 